\title{
Approximate Solutions of Singularly Perturbed Nonlinear Ill-posed and Sixth-order Boussinesq Equations with Hybrid Method
}

\author{
Derya ARSLAN* \\ Department of Mathematics, Faculty of Art and Science, University of Bitlis Eren, 13200, Bitlis, Turkey \\ (ORCID: 0000-0001-6138-0607)
}

\begin{abstract}
The aim of this paper is to obtain the approximate solution of singularly perturbed ill-posed and sixth-order Boussinesq equation by hybrid method (differential transform and finite difference method) as a different alternative method. Differential transform method is applied for $t$-time variable and the finite difference method (central difference approach) is applied for $x$-position variable. Two examples are presented to demonstrate the efficiency and reliability of the hybrid method. Numerical results are given and compared with exact solution and in literature RDTM solution. The numerical data show that hybrid method is a powerful, quite efficient and is practically well suited for solving nonlinear singular perturbed Boussinesq equations.
\end{abstract}

Keywords: Sixth-order Boussinesq Equation, Differential Transform Method, Finite Difference Method, Approximate Solution.

\section{Hibrit Metot ile Singüler Pertürbe Nonlineer Ill-posed ve Altıncı Mertebe Boussinesq Denklemlerinin Yaklaşık Çözümleri}

\begin{abstract}
$\ddot{\mathbf{O} z}$
$\mathrm{Bu}$ çalışmanın amacı, singüler pertürbe lineer olmayan ill-posed ve altıncı mertebeden Boussinesq denkleminin farklı bir alternatif yöntem olan hibrit metotla (diferansiyel dönüşüm ve sonlu fark metodu) yaklaşı çözümünü elde etmektir. $t$-zaman değişkeni için diferansiyel dönüşüm metodu ve $x$-konum değişkeni için sonlu fark metodu (merkezi fark yaklaşımı) uygulanmıştır. Hibrit yöntemin etkinliğini ve güvenilirliğini göstermek için iki örnek sunulmuştur. Nümerik sonuçlar, kesin çözüm ve literatürde yer alan RDTM çözümü ile karşılaştırılmıştır. Sayısal veriler bu yöntemin güçlü, oldukça etkili olduğunu ve nonlineer singüler pertürbe Boussinesq denklemlerini çözmek için pratik olarak uygun olduğunu göstermektedir.
\end{abstract}

Anahtar kelimeler: Altıncı Mertebe Boussinesq Denklemi, Ill-posed Boussinesq Denklemi, Diferansiyel Dönüşüm Metodu, Sonlu Fark Metodu, Yaklaşık Çözüm.

\section{Giriş}

Boussinesq equation was modeled by Boussinesq in 1872 [1]. Singularly perturbed Boussinesq equation as a dispersive regularization of the ill-posed classical Boussinesq equation for $\varepsilon=0$ was introduced by Darapi and Hua [2]. The Boussinesq equation is a classical nonlinear equation, which describes the wave phenomenon of physics, and has been widely studied in many fields of physics [3]. There are many documents about these equations such as Z. Feng [4] studied the generalized Boussinesq equation including the singularly perturbed Boussinesq equation, C. Song, H. Li, and J. Li [5] investigated the initial boundary value problem for the singularly perturbed Boussinesq-type equation. Other studies on singularly perturbed Boussinesq equation can be seen in references [2,3,5,6,10-12]. Recently, some powerful and efficient techniques for solving singular perturbed boussinesq equation have used by many mathematicians and physical scientists such as reduced differential transform method [6], homotopy

*Sorumlu yazar: ayredlanu@gmail.com

Geliş Tarihi: 03.12.2018, Kabul Tarihi: 30.03.2019 
perturbation method [7] and so on. Hybrid method is also preferred in the solution of many linear and nonlinear problems (see, for instance, [7,12,17-23]).

In this study, the following ill-posed for $\varepsilon=0$ in Eq. (1) and sixth-order singularly perturbed Boussinesq equation for $\varepsilon=\frac{1}{2}$ in Eq. (2) is examined for the first time by hybrid method:

$$
u_{t t}=u_{x x}+u_{x x}^{2}+u_{x x x x}
$$

and

$$
u_{t t}=u_{x x}+u_{x x}^{2}+u_{x x x x}+\varepsilon u_{x x x x x x} .
$$

The procedure of the method includes the use of differential transform method based on the $t$-time variable in the ill-posed and sixth order Boussinesq equation and then the central difference method based on the $x$-position variable and iteration equation is obtained. Then, $Y(i, k)$ terms for $k=0,1,2,3, \ldots$ are obtained. If these terms are written in Equation (4), a series solution or a solution based on mesh points is obtained. Finally, the solution is compared to the exact and RDTM solution [6]. So the effectiveness and applicability of the hybrid method is shown.

This study is organized as follows: Ill- posed and sixth order Boussinesq equation are analyzed by hybrid method (differential transform and finite difference methods). The properties of the ill-posed and sixth order Boussinesq equation are given in the introduction. Hybrid method is defined. The hybrid method is applied to two examples. In the series solution, obtained with the above-mentioned application, the exact and approximate solution values are presented with graphs and tables for some values of $x_{i}$ and $t$. Then, these solutions are compared with in the literature [6].

The differential transform method was initially used by Zhou for the solution of linear and nonlinear problems in electrical circuit analysis [26]. Based on the definition and properties of the differential transform method, solution of $u(x, t)$ for the differential transform function $U(i, k)=$ $U\left(x_{i}, k\right)$ that corresponds to the two-variable $u(x, t)$ function, where $x_{i}=i \square, \mathrm{h}$ is the finite difference step interval and $i=0,1,2,3, \ldots$, based on $t$-time variable is described as follows [8,9]:

$$
u(x, t)=\sum_{k=0}^{\infty} U(i, k) t^{k}=U(i, 0)+U(i, 1) t+U(i, 2) t^{2}+\cdots .
$$

The differential transform of $u(x, t)$ based on $t$ - time variable is defined as follows [8,9]:

$$
U(i, k)=\frac{1}{k !}\left[\frac{d^{k}}{d t^{k}} u(x, t)\right]_{t=0} .
$$

The inverse of the $U(i, k)$ differential function based on $t$ is defined as follows [8,9]:

$$
u(x, t)=\sum_{k=0}^{\infty} U(i, k) t^{k} .
$$

Using the above-mentioned equations and certain mathematical operations, some features of the differential transform method $[8,9,18,25,28]$ are presented in Table 1 . These properties will be used to solve the ill-posed and sixth order Boussinesq equation.

Table 1. Some properties of differential transform based on $t$ and $x$ variable

\begin{tabular}{|l|l|}
\hline Function & Transform \\
\hline$\frac{d^{2} w(x, t)}{d t^{2}}$ & $W(i, k)=(k+1)(k+2) W(i, k+2)$ \\
\hline$w(x, t)=c, \quad c$ is constant & $W(i, k)=c$ \\
\hline
\end{tabular}

Central difference derivations are defined as

$$
\begin{gathered}
\frac{\partial^{2} u}{\partial x^{2}} \rightarrow \frac{u(i+1, k)-2 u(i, k)+u(i-1, k)}{\square^{2}}, \\
\frac{\partial^{4} u}{\partial x^{4}} \rightarrow \frac{u(i+2, k)-4 u(i+1, k)+6 u(i, k)-4 u(i-1, k)+u(i-2, k)}{\square^{4}},
\end{gathered}
$$


$\frac{\partial^{6} u}{\partial x^{6}}$
$\rightarrow \frac{u(i-3, k)-6 u(i-2, k)+15 u(i-1, k)-20 u(i, k)+15 u(i+1, k)-6 u(i+2, k)+u(i+3, k)}{\square^{6}}$.

\section{Application of the Hybrid Method}

In this section, we present two examples to show the effectiveness of hybrid method. The results are compared with [6] and shown in Table 1 and Table 2. The algorithms are computed by computer program.

\section{Example 2. 1}

We consider the following singularly perturbed sixth-order Boussinesq equation [6] for $\varepsilon=\frac{1}{2}$, where, $\varepsilon \in(0,1)$ is a very small perturbation parameter:

with initial conditions

$$
u_{t t}=u_{x x}+u_{x x}^{2}-u_{x x x x}+\frac{1}{2} u_{x x x x x x}
$$

$$
u(x, 0)=\frac{-105}{169} \sec \square^{4}\left(\frac{x}{\sqrt{26}}\right), \quad u_{t}(x, 0)=\frac{-210}{2197} \sqrt{\frac{194}{13}} \sec \square 4\left(\frac{x}{\sqrt{26}}\right) \tan \square\left(\frac{x}{\sqrt{26}}\right),
$$

and exact solution are given by

$$
u(x, t)=-\frac{105}{169} \sec \square^{4}\left[\frac{1}{\sqrt{26}}\left(x-\sqrt{\frac{97}{169}} t\right)\right] .
$$

By hybrid method, the solution procedure is given as follows:

Firstly, differential transforms of terms dependent on $t$ - time variable in the sixth-order singularly perturbed Boussinesq equation (6)-(7) are found by using the differential transform method. Secondly, the central differences of derivative terms dependent on the $x$-position variable are found. The $x$-position variable is replaced with $x_{i}$ mesh points in the equation (6)-(7). Finally, we obtain the recurrence relation.

$$
\begin{aligned}
& u_{t t} \rightarrow(k+1)(k+2) U(i, k+2) \text {, } \\
& u_{x x} \rightarrow \frac{U(i+1, k)-2 U(i, k)+U(i-1, k)}{\square^{2}}, \\
& u_{x x x x} \rightarrow \frac{U(i+2, k)-4 U(i+1, k)+6 U(i, k)-4 U(i-1, k)+U(i-2, k)}{\square^{4}}, \\
& \begin{array}{l}
u_{x x x x x} \\
\rightarrow \frac{U(i-3, k)-6 U(i-2, k)+15 U(i-1, k)-20 U(i, k)+15 U(i+1, k)-6 U(i+2, k)+U(i+3, k)}{\square^{6}},
\end{array} \\
& u(x, 0) \rightarrow \frac{-105}{169} \sec \square^{4}\left(\frac{x_{i}}{\sqrt{26}}\right), \\
& u_{t}(x, 0) \rightarrow \frac{-210}{2197} \sqrt{\frac{194}{13}} \sec \square^{4}\left(\frac{x_{i}}{\sqrt{26}}\right) \tan \square\left(\frac{x_{i}}{\sqrt{26}}\right),
\end{aligned}
$$




$$
\begin{aligned}
& U(i, k+2) \\
& =\frac{1}{(k+1)(k+2)}\left[\frac{U(i+1, k)-2 U(i, k)+U(i-1, k)}{\square^{2}}+\frac{(U(i+1, k)-2 U(i, k)+U(i-1, k))^{2}}{\square^{4}}\right. \\
& -\frac{U(i+2, k)-4 U(i+1, k)+6 U(i, k)-4 U(i-1, k)+U(i-2, k)}{\square^{4}} \\
& \left.+\frac{U(i-3, k)-6 U(i-2, k)+15 U(i-1, k)-20 U(i, k)+15 U(i+1, k)-6 U(i+2, k)+U(i+3, k)}{2 \square^{6}}\right] .
\end{aligned}
$$

In this recurrence relation given above, $U(i, 2), U(i, 3), U(i, 4), \ldots$ differential transform coefficients are found for $k=0,1,2,3, \ldots$ values with 10 iterations. When these differential transform coefficients are written in Equation (3) for $x_{i}=i \square, \square=0.1$ and $i=0,1,2, \ldots$, we obtain as

$$
\begin{aligned}
& x_{i}=0, \quad u(0, t)=\sum_{k=0}^{\infty} U(0, k) t^{k}=U(0,0)+U(0,1) t+U(0,2) t^{2}+\cdots \\
& =-0.6213017751+0 t+(0.5486233244 e-1) t^{2}+\ldots-0.6213017749 t^{10}, \\
& x_{i}=0.1, \quad u(0.1, t)=\sum_{k=0}^{\infty} U(0.1, k) t^{k}=U(0.1,0)+U(0.1,1) t+\cdots \\
& =-0.6208240650+(-0.7235058176 e-2) t \\
& +(0.5488338737 e-1) t+\cdots-0.6208247882 t^{10}, \\
& x_{i}=1, \quad u(1, t)=\sum_{k=0}^{\infty} U(1, k) t^{k}=U(1,0)+U(1,1) t+U(1,2) t^{2}+\cdots \\
& =-0.5755821336 \pm(0.6623964847 e-1) t+(0.5654247317 e-1) t^{2} \ldots-0.5755887573 t^{10} .
\end{aligned}
$$

Approximate solutions on $x_{i}$ mesh points for $t=0.01$ are obtained and presented in Table 2 . When the results are compared to RDTM [6], as seen from Table 2, the difference between the results is quite low. Figure 1 shows hybrid method, exact solution and comparison of them for different values of $x$.

Tablo 2. Comparison of numerical results with literature [6] for $t=0.01$

\begin{tabular}{ccccc}
\hline$x$ & Exact solution & Hybrid approximate solution & Error & RDTM solution [6] \\
\hline 0.0 & -0.6213017749 & -0.6213639113 & $0.621364 \mathrm{e}-4$ & -0.6210321299 \\
0.1 & -0.6208247882 & -0.6208868769 & $0.620887 \mathrm{e}-4$ & \\
0.2 & -0.6193949466 & -0.6194568923 & $0.619457 \mathrm{e}-4$ & \\
0.3 & -0.6170199269 & -0.6170816351 & $0.617082 \mathrm{e}-4$ & \\
0.4 & -0.6137124382 & -0.6137738155 & $0.613773 \mathrm{e}-4$ & -0.6139924936 \\
0.5 & -0.6094900924 & -0.6095510475 & $0.609551 \mathrm{e}-4$ & \\
0.6 & -0.6043752245 & -0.6044356680 & $0.604435 \mathrm{e}-4$ & \\
0.7 & -0.5983946672 & -0.5984545127 & $0.598455 \mathrm{e}-4$ & \\
0.8 & -0.5915794829 & -0.5916386467 & $0.591638 \mathrm{e}-4$ & -0.5921188393 \\
0.9 & -0.5839646569 & -0.5840230592 & $0.584023 \mathrm{e}-4$ & \\
1.0 & -0.5755887573 & -0.5756463220 & $0.575647 \mathrm{e}-4$ & -0.5762424655 \\
\hline
\end{tabular}




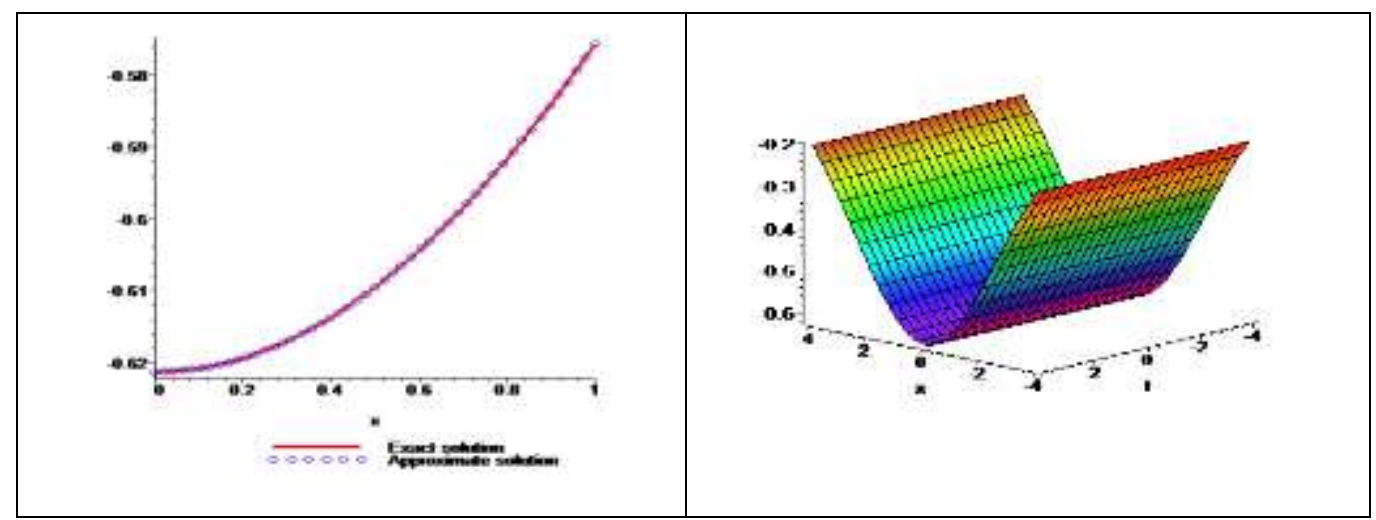

Şekil 1. Comparison of exact and approximate solution curves for example 1

\section{Example 2. 2}

Now, we will give the following ill-posed Boussinesq equation [6] for $\varepsilon=0$ :

with the initial conditions

$$
u_{t t}=u_{x x}+3 u_{x x}^{2}-u_{x x x x}
$$

$$
u(x, 0)=\frac{2 a k^{2} e^{k x}}{\left(1+a e^{k x}\right)^{2}}, \quad u_{t}(x, 0)=\frac{2 a s^{3} e^{s x}\left(1-a e^{s x}\right) \sqrt{1+s^{2}}}{\left(1+a e^{s x}\right)^{3}},
$$

where $a$ and $s$ are arbitrary constants. The exact solution of this problem is given as

$$
u(x, t)=\frac{2 a k^{2} e^{k x+k \sqrt{1+k^{2} t}}}{\left(1+a e^{k x+k \sqrt{1+k^{2} t}}\right)^{2}} .
$$

The following differential transforms and the central differences are written by hybrid method in the (8)-(9)

$$
\begin{gathered}
u_{t t} \rightarrow(k+1)(k+2) U(i, k+2), \\
u_{x x} \rightarrow \frac{U(i+1, k)-2 U(i, k)+U(i-1, k)}{\square^{2}}, \\
u_{x x x x} \rightarrow \frac{U(i+2, k)-4 U(i+1, k)+6 U(i, k)-4 U(i-1, k)+U(i-2, k)}{\square^{4}}, \\
u(x, 0) \rightarrow U(i, 0)=\frac{2 a k^{2} e^{k x_{i}}}{\left(1+a e^{\left.k x_{i}\right)^{2}}\right.} \\
u_{t}(x, 0) \rightarrow U_{t}(i, 0)=\frac{2 a s^{3} e^{s x_{i}}\left(1-a e^{s x_{i}}\right) \sqrt{1+s^{2}}}{\left(1+a e^{s x_{i}}\right)^{3}},
\end{gathered}
$$

and then the recurrence relation is obtained as following:

$$
\begin{aligned}
U(i, k+2)= & \frac{1}{(k+1)(k+2)}\left[\frac{U(i+1, k)-2 U(i, k)+U(i-1, k)}{\square^{2}}\right. \\
& +\frac{3(U(i+1, k)-2 U(i, k)+U(i-1, k))^{2}}{\square^{4}} \\
& \left.-\frac{U(i+2, k)-4 U(i+1, k)+6 U(i, k)-4 U(i-1, k)+U(i-2, k)}{\square^{4}}\right],
\end{aligned}
$$

where $U(i, 2), U(i, 3), U(i, 4), \ldots$ differential transform coefficients are obtained for $k=0,1,2,3, \ldots$. If these differential transform coefficients are written in the equation (3) for $x_{i}=i \square, \square=0.1$ and $i=$ $0,1,2, \ldots$, we have the following solutions 


$$
\begin{aligned}
& x_{i}=0, \quad u(0, t)=\sum_{k=0}^{\infty} U(0, k) t^{k}=U(0,0)+U(0,1) t+U(0,2) t^{2}+\cdots \\
& =1+0 t+\cdots+0.3923166756 t^{10}, \\
& x_{i}=0.01, \quad u(0.01, t)=\sum_{k=0}^{\infty} U(0.01, k) t^{k}=U(0.01,0)+U(0.01,1) t+U(0.01,2) t^{2}+\cdots \\
& =1-0.03523773790 t+\cdots+0.4272669580 t^{10} \text {, } \\
& x_{i}=1, \quad u(1, t)=\sum_{k=0}^{\infty} U(1, k) t^{k}=U(1,0)+U(1,1) t+U(1,2) t^{2}+\cdots \\
& =1-0.2569845178 t+\cdots+0.9194087280 t^{10} .
\end{aligned}
$$

We only use 10 iterations to get a very good error. Then, approximate solutions on $x_{i}$ mesh points for $t=0.01, a=1, s=1$ are obtained. Numerical comparison between RDTM [6] and hybrid method are found in Table 3 which shows hybrid method is more promising. The plot of exact, hybrid solution and comparison of them are shown in Figure 2.

Tablo 3. Comparison of numerical results with literature [6] for $t=0.01$

\begin{tabular}{ccccc}
\hline$x$ & Exact solution & Hybrid approximate solution & Error & RDTM solution [6] \\
\hline 0.0 & 0.3923166756 & 0.3962794703 & 0.0039627947 & 0.4999750000 \\
0.1 & 0.3738036936 & 0.3420113793 & 0.0317923143 & \\
0.2 & 0.3548355830 & 0.2941070357 & 0.0607285473 & \\
0.3 & 0.3356369702 & 0.2520482790 & 0.0835886912 & \\
0.4 & 0.3164133330 & 0.2153102515 & 0.1011030815 & 0.4791589895 \\
0.5 & 0.2973483516 & 0.1833742217 & 0.1139741299 & \\
0.6 & 0.2786023734 & 0.1557379550 & 0.1228644184 & \\
0.7 & 0.2603118678 & 0.1319236644 & 0.1283882034 & \\
0.8 & 0.2425897230 & 0.1114837044 & 0.1311060186 & 0.4255084686 \\
0.9 & 0.2255262178 & 0.0940042490 & 0.1315219687 & \\
1.0 & 0.2091905022 & 0.0791072428 & 0.1300832593 & 0.3906469564 \\
\hline
\end{tabular}

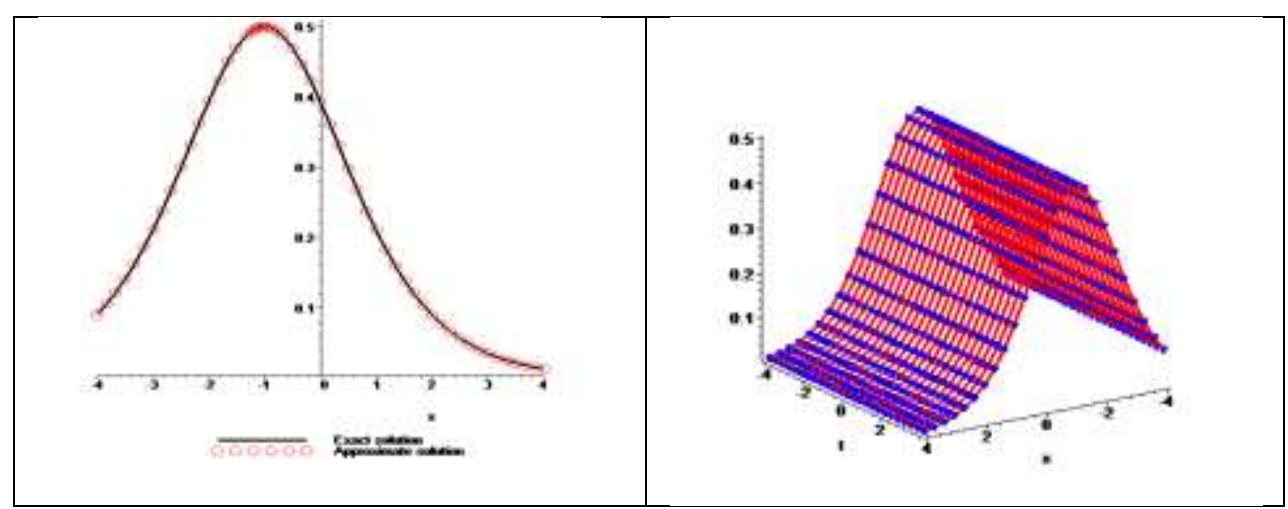

Şekil 2. Comparison of exact and approximate solution curves for example 2

\section{Conclusion}

In this study, we applied hybrid method to construct approximate solution of singularly perturbed illposed and sixth-order Boussinesq equations. Present approximate solution converged to the exact solution of the singularly perturbed ill-posed and sixth-order Boussinesq equations and also compared with RDTM approximate solution of [6]. According to obtained results from examples, it was observed that the hybrid method was very convenient to apply and very useful for finding solutions of nonlinear problems. The main advantage of the hybrid method was to provide the user an analytical approximation 
to the solution, in many cases, an exact solution, in a rapidly convergent sequence with elegantly computed terms. We can definitely say that hybrid method should be preferred for solving other partial differential equations.

\section{Acknowledgment}

The author would like to express his appreciation and gratitude to the editor and the anonymous referees for their comments and suggestions on this paper.

\section{References}

[1] Boussinesq J. 1872. Théorie des ondes et de remous qui se propagent le long d'un canal rectangulaire horizontal, en communiquant au liquide contenu dans ce canal des vitesses sensiblement pareilles de la surface au fond. Journal Mathematiques Pures Appliquees, 17: 55108.

[2] Darapi P., Hua W. 1999. A Numerical Method for Solving an ill-posed Boussinesq Equation Arising in Water Waves and Nonlinear Lattices. Applied Mathematics and Computation, 101: 159-207.

[3] Dash R.K., Daripa P. 2002. Analytical and Numerical Studies of Singularly Perturbed Boussinesq Equation, Applied Mathematics and Computation, 126: 1-30.

[4] Feng Z. 2003. Traveling Solitary Wave Solutions to the Generalized Boussinesq Equation. Wave Motion, 37 (1): 17-23.

[5] Song C., Li H., Li J. 2013. Initial Boundary Value Problem for the Singularly Perturbed Boussinesq-Type Equation. Discrete and Continuous Dynamical Systems, 2013: 709-717.

[6] Cakır M., Arslan D. 2016. Reduced Differential Transform Method for Singularly Perturbed Sixth-Order Boussinesq Equation. Mathematics and Statistics: Open Access, 2 (2): MSOA-2-014.

[7] Yilmazer R., Bas E. 2012. Explicit Solutions of Fractional Schrödinger Equation via Fractional Calculus Operators, International Journal of Open Problems in Computer Science and Mathematics, 238: 1-10.

[8] Ayaz F. 2004. Solution of the System of Differential Equations by Differential Transform Method. Appl. Math. Comput., 147: 547-567.

[9] Ayaz F. 2004. Applications of Differential Transform Method to Differential Algebraic Equations. Appl. Math. Comput., 152: 649-657.

[10] Duran S., Askin M., Tukur A.S. 2017. New Soliton Properties to the Ill-posed Boussinesq Equation arising in Nonlinear Physical Science. An International Journal of Optimization and Control: Theories \& Applications, 7 (3): 240-247.

[11] Gao B., Tian H. 2015. Symmetry Reductions and Exact Solutions to the Ill-Posed Boussinesq. International Journal of Non-Linear Mechanics, 72: 80-83.

[12] Süngü İ., Demir H. 2012. Solutions of the System of Differential Equations by Differential Transform / Finite Difference Method. Nwsa-Physical Sciences, 7: 1308-7304.

[13] Süngü İ., Demir H. 2012. Application of the Hybrid Differential Transform Method to the Nonlinear Equations. Applied Mathematics, 3: 246-250.

[14] Yeh Y.L., Wang C.C., Jang M.J. 2007. Using Finite Difference and Differential Transformation Method to Analyze of Large Deflections of Orthotropic Rectangular Plate Problem. Applied Mathematics and Computation, 190: 1146-1156.

[15] Chu H.P., Chen C.L. 2008. Hybrid Differential Transform and Finite Difference Method to Solve the Nonlinear Heat Conduction Problem. Communication in Nonlinear Science and Numerical Simulation, 13: 1605-1614

[16] Chu S.P. 2014. Hybrid Differential Transform and Finite Difference Method to Solve the Nonlinear Heat Conduction Problems. WHAMPOA - An Inter disciplinary Journal, 66: 15-26.

[17] Chen C.K., Lai H-Y., Liu C.C. 2009. Nonlinear Micro Circular Plate Analysis Using Hybrid Differential Transformation / Finite Difference Method. CMES, 40: 155-174.

[18] Arslan D. 2019. A Novel Hybrid Method for Singularly Perturbed Delay Differential Equations. Gazi University Journal of Sciences, 32 (1): 217-223. 
[19] Bas E., Metin Türk, F. 2018. An Application of Comparison Criteria to Fractional Spectral Problem Having Coulomb Potential. ThermalScience, 22 (1): 79-S85.

[20] Bas E., Ozarslan R. 2018. Real World Applications of Fractional Models by Atangana-Baleanu Fractional Derivative. Chaos, Solitons \& Fractals, 116: 121-125

[21] Bas E., Ozarslan R., Baleanu D., Ercan A. 2018. Comparative Simulations for Solutions of Fractional Sturm-Liouville Problems with Nonsingular Operators, Advances in Difference Equations, 2018 (1): 350.

[22] Bas E., Acay B., Ozarslan R. 2019. Fractional Models with Singular and Non-Singular Kernels for Energy Efficient Buildings. Chaos: An Interdisciplinary Journal of Nonlinear Science, 29 (2): 023110.

[23] Bas E., Ozarslan R. 2017. Sturm-Liouville Problem via Coulomb Type in Difference Equations. Filomat, 31 (4): 989-998.

[24] Daripa P., Dash R.K. 2001. Weakly Non-local Solitary Wave Solutions of a Singularly Perturbed Boussinesq Equation. Mathematics and Computers in Simulation, 55: 393-405.

[25] Arslan D. 2018. Differential Transform Method for Singularly Perturbed Singular Differential Equations. Journal of the Institute of Natural \&Applied Sciences, 23 (3): 254-260.

[26] Zhou J.K. 1986. Differential Transformation and its Applications for Electrical Circuits. Huazhong University Press, Wuhan, China.

[27] Song C., Li J., Gao R. 2014. Nonexistence of Global Solutions to the Initial Boundary Value Problem for the Singularly Perturbed Sixth-Order Boussinesq-Type Equation. Journal of Applied Mathematics, 2014: 7 pages.

[28] Arslan D. 2018. The Approximate Solution of Fokker-Planck Equation with Reduced Differential Transform Method. Erzincan UniversityJournal of Science and Technology, 12 (1): 281-293.

[29] Mohyud-Din S.T., Muhammad Aslam N. 2009. Homotopy Perturbation Method for Solving Partial Differential Equations. Zeitschrift Naturforschung, 64: 157-170. 